\title{
Obstetric Vesico-vaginal Fistulae: A Documentary Review of Women Managed in Mendefera Zonal Referral and National Fistula Hospital, Eritrea
}

\author{
Dawit Sereke $^{1,}$ * , Habte Hailemelecot ${ }^{1}$, Yirgalem Issak ${ }^{1}$, Dawit Estifanose ${ }^{2}$ \\ ${ }^{1}$ Department of Obstetrics and Gynecology, Mendefera Zonal Referral and National Fistula Hospital, Mendefera, Eritrea \\ ${ }^{2}$ Department of Obstetrics and Gynecology Orotta National Referral Maternity Hospital, Asmara, Eritrea
}

Email address:

weldegebrealdawit@gmail.com (D. Sereke)

${ }^{*}$ Corresponding author

To cite this article:

Dawit Sereke, Habte Hailemelecot, Yirgalem Issak, Dawit Estifanose. Obstetric Vesico-vaginal Fistulae: A Documentary Review of Women Managed in Mendefera Zonal Referral and National Fistula Hospital, Eritrea. Science Journal of Public Health.

Vol. 8, No. 5, 2020, pp. 149-154. doi: 10.11648/j.sjph.20200805.13

Received: July 9, 2020; Accepted: August 4, 2020; Published: October 7, 2020

\begin{abstract}
Background: obstetric fistula is a devastating childbirth injury as a result of obstructed labor. It leads to chronic urinary incontinence and, in most cases, significant physical and emotional suffering. Its prevalence is high in Sab-Sahara African and South Asian countries. The objective of this study is to determine the incidence and describe the characteristics of women with obstetric Vesico-vaginal fistula. Methods: A retrospective cross-sectional study was conducted in all obstetric vesico-vaginal fistula patients. Patient identification performed through review of prerecorded logbook and patient card describing each patient admitted to fistula ward over a period of five years from January $1^{\text {st }} 2014$ to December 31, 2018. Medical records were reviewed to obtain data on socio-demographic and obstetric characteristics, clinical details, and treatment. Statistical analysis was performed using STATA-9. Results: There were 146 women with Vesico-vaginal fistula (VVF) admitted to the fistula hospital over the study period; of which 144 of them were obstetric fistula. During the study period the total number of health facility deliveries in Eritrea was 217,119 giving an estimated rate of obstetric VVF of $0.7 / 1000$ facility deliveries. The median age, parity, and number of live births was 30,3 , and 2 , respectively. One quarter $(n=37)$ of the cases being in the age group of 20 years or younger. The highest incidence of VVF $(38 \%)$ was observed in Primiparous. $75 \%$ gave birth in a health facility, $54 \%$ of deliveries were by caesarean section, and $80 \%$ of babies were stillborn. 77\% of repairs were successful. Conclusion: The incidence of fistula in Eritrea is relatively low as compared to other sub-Saharan African countries. In this study, age at fistula development was older than usually found, which might be due to poor access to emergency obstetric care (EmOC) that contributed more to this problem.
\end{abstract}

Keywords: Incidence, Obstetric Fistula, Vesico-vaginal Fistula

\section{Introduction}

For every maternal death, additional 20-30 women develop serious pregnancy-related complicati4ons [1]. Among all maternal morbidities, obstetric fistula (OF) is one of the most devastating conditions caused by injury during childbirth resulting in urinary and/or fecal incontinence [1-3]. World Health Organization (WHO) defines obstetric fistula $(\mathrm{OF})$ as an abnormal connection between the vagina, rectum and/or bladder which may develop after prolonged and obstructed labour and lead to continuous urinary or fecal incontinence [2]. Vesico-vaginal fistula (VVF), a subtype of female urogenital fistula (UGF), is an abnormal fistulous tract extending between the bladder and the vagina that allows the continuous involuntary discharge of urine into the vaginal vault. Recto-vaginal (RVF) is an abnormal fistulous tract between the vagina and rectum that allows continuous fecal leak (1-3).

Urogenital fistula (UGF) may occur congenitally, but are most often acquired from obstetric, surgical, radiation, malignant and other causes (3). Over $90 \%$ of fistulas in low and middle income countries (LMIC) are of obstetrics 
etiology whereas over $70 \%$ of the cases in high income countries are as result of pelvic surgery [3, 4]. In LMICs, the development of $\mathrm{OF}$ is directly linked to obstructed labour which is one of the major causes of maternal mortality and morbidity [3-5]. Risk factors for OF commonly reported include the place of birth, the duration of labor, the lack of prenatal care, early marriage and young age at delivery $[5,6]$. Majority of obstetric fistula in Zambia (95.5\%), Ethiopia $(92 \%)$, and Niger $(85 \%)$ were reported to have history of labor lasting more than 24 hours, lack of antenatal attendance, and home deliveries respectively [5].

OF mostly confined to the "fistula belt" across the northern half of Sub-Saharan African countries or south Asia with poorly resourced health system $[3,5,7]$. Globally, but mainly in parts of Sub-Saharan Africa and Asia, estimates suggest that more than 2 million young women live with untreated OF, with 50000 to 100000 new cases each year adding to the back log [7-12]. In a systematic review study conducted by Adler et al 2013, the pooled prevalence worldwide and in different regions were documented as 0.29 per 1000 women of reproductive age globally [7, 13], 1.60 for sub Saharan Africa and 1.20 for South Asia [7]. In 2013 Ethiopia had about 142,387 cases of VVF with an incidence of 10.6/1000 women who have ever given birth [13]. The incidence rate of $\mathrm{OF}$ in Nigeria and Uganda is 2-5/1000 deliveries and $2.6 \%$ to $2.8 \%$ in women of reproductive age respectively [12].

OF is still woefully neglected in LMICs despite its devastating impact on the lives women. It has remained an overlooked problem for it affects some of the most ostracized members of the population [2]. It often occurs in primiparous, babies' usually stillborn and secondary infertility is common $[14,15]$. Other consequences include high divorce rate reaching 50 to $90 \%$, severe social stigmatization and loss of support from families and communities [10, 11, 13, 15-18]. These problems of fistula are likely to persist until quality basic and comprehensive health care services reach the poorest and most vulnerable members of society [ 8,9 , and 14]. In low resource setting, it is one of the most visible indicators of the failure of health systems to deliver accessible, timely and appropriate intrapartum care [8, 10-12].

Once OF occur, most of them require surgical repair; they usually cannot heal by them- selves [14]. The best chance of fistula closure is generally agreed to be at the time of the first operation. According to a study reported by Hilton et al in a large series of 2484 OF patients' shows successful fistula closure in $81 \%$ of patients at the first attempt, whereas successful closure was achieved in only $65 \%$ of patients who needed two or more operations [3].

Eritrea has joined the global campaign to end fistula since 2003. The 2010 Eritrean Population and Health Survey (EPHS) found 102 Eritrean women with history of fistula among 30,244 women interviewed which gives a total rate of $0.34 \%$. Majority (56 percent) reported experiencing fistula symptoms after delivery [19]. From this period of time on there was no research or investigation that was done to show the magnitude of the problem in the country. MZRNFH has provided support including surgical repair to these women since2008. This study was aimed at establishing the incidence, clinical detail, and management outcome of VVF cases, and to assess the characteristics of women with this problem at MZRNFH.

\section{Methods}

\subsection{Study Setting and Design}

The study was a retrospective clinical record view. It was conducted at MZRNFH on women who were admitted with the diagnosis of obstetrics fistula from January 1st 2014 to December 31, 2018. The Hospital is a Zonal Referral and National fistula hospital responsible for the management and follow-up of all procedures related to obstetrics and gynecologic problems, including the provision of 24-hour emergency obstetric care services. It is situated in the southern region of Eritrea at the city of Mendefera. Women with OF from all over the country travel to this hospital because it is the only hospital which provides regular fistula repair.

\subsection{Study Participants and Study Period}

All women who were admitted with the diagnosis of VVF of obstetrics origin at MZRNFH, from Jan 1st 2014 to Dec 312018 were included.

\subsection{Data Collection}

Primarily data were collected by review of the prerecorded log book and case notes of women who were admitted to Fistula ward with the diagnosis of VVF. Information had been recorded on each woman using a standardized questionnaire. Based on this, medical records were reviewed and pertinent maternal information was recorded starting with socio-demographic characteristics and going through obstetrics, gynecological, medical and surgical history. This includes the women's age, religion, address, marital status, obstetric history; operative diagnosis, details of the fistula and surgical outcome. The collected data were cleaned and checked for completeness and reliability before data entry.

\subsection{Data Processing and Analysis}

The study used STATA 9 for Statistical analysis of the data collected.

\section{Results}

There were 146 women with VVF admitted to the hospital over the study period; of which 144 of them were obstetric fistula and the rest two were related to gynecological operation. The incidence of VVF per year was 29. During the study period, the total number of health facility deliveries and expected deliveries in Eritrea was 217,119 and 554,705 
(EHMIS 2018) respectively giving an estimated rate of obstetric Vesico-vaginal fistula of 0.7/1000 facility deliveries or 25/100000 expected deliveries. The results of the study indicated that, the median age, parity, and number of live births was 30,3 , and 2 , respectively. The minimum and maximum age of the study group was 16 and 65 years respectively. One quarter of $(n=37)$ of the cases being in the age group of 20years or younger. Only 4 (3\%) women were under the age of 18 . The highest incidence of VVF $(38 \%)$ was observed in Primiparous although the range of the parity was up to 10 (Table 1). Of the total of 429 babies born to these women, only $267(62 \%)$ were still alive. One third of the women $(n=47)$ were childless.

Table 1. Characteristics of women with Vesico-vaginal fistula.

\begin{tabular}{ll}
\hline Characteristics & N (\%) \\
\hline Age (years) & $37(25)$ \\
$<=20$ & $50(35)$ \\
$21-30$ & $43(30)$ \\
$31-40$ & $10(7)$ \\
$41-50$ & $4(3)$ \\
$>50$ & \\
Parity & $54(38)$ \\
Para 1 & $56(39)$ \\
Para2-4 & $34(23)$ \\
Grand multiparous & \\
Religion & $70(48)$ \\
Christian & $75(52)$ \\
Muslim & \\
Address & $57(40)$ \\
Gash Barka & $29(20)$ \\
Debub &
\end{tabular}

\begin{tabular}{ll}
\hline Characteristics & N $(\%)$ \\
\hline Northern red sea & $23(16)$ \\
Anseba & $19(13)$ \\
Meakel & $9(6)$ \\
Southern red sea & $7(5)$ \\
Marital status & \\
Married & $135(93)$ \\
Separated & $3(2)$ \\
Divorced & $5(4)$ \\
Widowed & $2(1)$ \\
\hline
\end{tabular}

The incidence of fistula was observed to decrease from year to year. Starring from 2015, its incidence was declined from 40 per year to 18 per year (figure 1). Five percent of these women $(n=7)$ has developed fistula for the second time following delivery. Majority (40\%) mothers with fistula came from region of Zoba Gash Barka followed by Zoba Debub $(20 \%)$ and the remaining $40 \%$ came from other Zobas. Ninety-three percent of women with fistula were married, $4 \%$ divorced, $2 \%$ separated, and $1 \%$ widowed. $52 \%$ of the women were Muslim and the rest $48 \%$ were Christian in religion (table 1). Of the total 144 babies born on the present delivery to these women, only $20 \%(n=28)$ were born alive. The majority of $(n=108)$ these women gave birth at the facility. For $58 \%$ of the women, their most recent delivery was by operative delivery (caesarean section or caesarean hysterectomy), and only $25 \%$ (21/83) of them end up with a live baby. Substantial proportion of these operations occurred due to ruptured uterus $(n=43)$ resulting in still birth delivery (table 2).

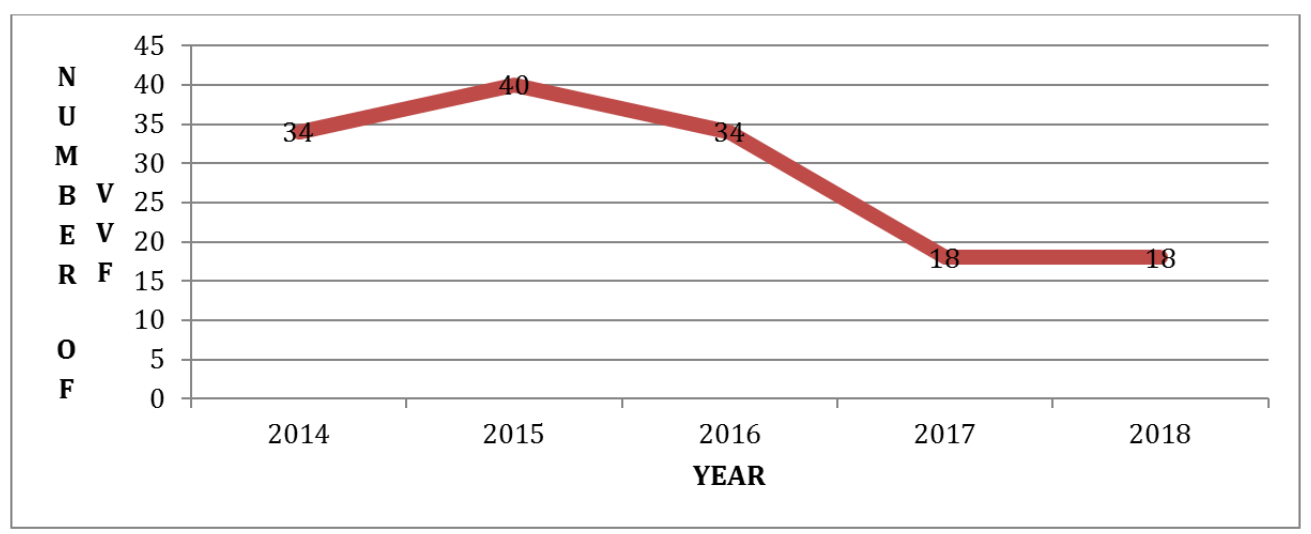

Figure 1. Annual incidence of VVF in MZRNFH.

Some of the clinical findings that were seen in these women was nerve damage resulting in foot drops, vulvar dermatitis and irritation, and associated fecal incontinence. Their incidence were $22 \%(\mathrm{n}=32), 54 \%(\mathrm{n}=78)$, and $2 \%$ $(n=3)$ respectively. The most frequent site of VVF was found to be mid-vaginal (45.8\%), followed by juxta-cervical $(27.8 \%)$ and urethrovesical (11.6\%). In women with a VVF, the size of the fistula was small in $47.9 \%$ of cases and medium in $29.8 \%$ and large or extensive in $16 \%$ (table 2).

Of the 144 VVF patients who were managed in MZRNFH, 11 (7.6) of them healed conservatively. Of the remaining 133 who underwent repair surgery, $102(77 \%)$ healed in the first attempt of operation and 21/31 (68\%) healed on the second attempt giving the cumulative cure rate of $1^{\text {st }}$ and $2^{\text {nd }}$ attempt operation $92.5 \%(123 / 133)$.

Table 2. Delivery characteristics and outcome of the operation of women with $V V F$

\begin{tabular}{lll}
\hline Characteristics & N (\%) \\
\hline Place of most recent delivery & \\
Home & $35(24.5)$. & \\
Health facility & $108(75.5)$ \\
Outcome of mos11t recent delivery & \\
$\quad$ Vaginal delivery & $54(47)$ \\
Still birth $\quad$ Cesarean & $56(49)$ & \multirow{2}{*}{$116(80)$} \\
& Others (cesarean hysterectomy) & $6(4)$ \\
\hline
\end{tabular}




\begin{tabular}{|c|c|c|c|}
\hline \multicolumn{2}{|c|}{ Characteristics } & \multicolumn{2}{|l|}{$\mathrm{N}(\%)$} \\
\hline Live & Vaginal & $7(25)$ & \\
\hline birth & Cesarean & $21(75)$ & $28(20)$ \\
\hline \multicolumn{4}{|c|}{ Location of fistula } \\
\hline Mid-v & & $66(45.8)$ & \\
\hline Juxta- & & $40(27.8)$ & \\
\hline Ureth & ical & $24(16.7)$ & \\
\hline Bladd & & $2(1.4)$ & \\
\hline Other: & & $12(8.3)$ & \\
\hline \multicolumn{4}{|c|}{ Size of the fistula } \\
\hline Small & & $69(47.9)$ & \\
\hline Mediu & $-3 \mathrm{~cm})$ & $43(29.8)$ & \\
\hline Large & cm) & $14(9.7)$ & \\
\hline Exten & $>5 \mathrm{~cm})$ & $9(6.3)$ & \\
\hline Others & & $9(6.3)$ & \\
\hline \multicolumn{4}{|c|}{ Success of the repair } \\
\hline Conse & & $11(7.6)$ & \\
\hline First a & & $102(70.8)$ & \\
\hline $2^{\text {nd }}$ att & & $21(14.6)$ & \\
\hline $3^{\text {rd }}$ or & & $7(4.9)$ & \\
\hline Failed & & $3(2.1)$ & \\
\hline
\end{tabular}

\section{Discussion}

This study has shown that most women with fistula were above the age of 18 even though one quarter of them were 20years or younger. The study findings were found to be inconsistent with other sub-Saharan African countries where majority of them were teenage pregnancies $[4-5,7,10,12$, $18,24]$ and this may explain also the reason for the decrease in incidence of VVF in this study. The study has also shown that there were great proportion multiparous and grand multiparous women who are similarly affected like primiparous women which is consistent to a recent study done in Zambia and Ethiopia $[18,24]$ but it was found to be different from the studies done in other Sub-Saharan countries [4-5, 7, 9]. This might show that multiparous women are also at risk to develop obstetric fistula and they should not be forgotten when addressing fistula.

The study findings show that the incidence of obstetrics VVF is decreasing from year to year for the last four years and its incidence is also lower than majority of sub-Saharan countries [7, 13]. This could have been resulted from continued improvements of maternal health care and a decrease in deliveries under the age of 18 . However there is significant regional dipartites in the occurrence of the problem that shows significantly a large proportion of women with VVF came from Gash Barka region despite high coverage of health facility (EHMIS 2018) [20]. This may be because Zoba Gash-Barka is a large, well-populated rural area, few hospitals who give EmOC, and limited and difficult transportation.

In this study large proportion of women with VVF was still married which is different from most studies that were conducted in many Sub-Saharan countries [5, 7, 14, 15]. This could be due vast coverage in a country mass media about cause, effect, prevention and management of fistula, community sensitization and mobilization by governmental and non-governmental organization in the country, and may be due to difference in the ease or acceptability of divorce in
Eritrea. Religion was observed to have no effect on the occurrence of the problem.

A high proportion of women with VVF end up delivering at a health facility and $80 \%$ them incurred fetal lose. These could be explained by the fact that most began their labour at home; only reaching health facility after the ischemic injury had occurred and the life of the fetus is jeopardized. In this study majority of them gave birth by caesarian section and only $25 \%$ of these deliveries results in a live born fetus because the majority of them came to the facility after ruptured uterus and this are explained by delay in seeking help to facility where comprehensive EmOC service is given. The fetal lose in mother with OF also suggests that their suffering not only from their physical condition but also from psychological setbacks due to the loss of the pregnancy. The findings were also found to be in line with studies from SubSaharan African countries [4, 22-24].

The study findings show that the dermatological manifestation and the neurological injury rate were in line to the study done in East Africa and Nigeria [22, 23]. In this study the majority of fistula occurred in mid-vaginal, which was in line to the study done in Ethiopia (58\%) and Nigeria $(47 \%)[18,23]$.

Obstetric fistulae are therapeutic challenges, even in the hands of staff dedicated to this type of treatment at a center that has a large caseload and long experience. In the present study the overall cure rate at $1^{\text {st }}$ and $2^{\text {nd }}$ attempt was $77 \%$ and $68 \%$ respectively, which was comparable to studies published by Hilton et al $[3,19]$.

\section{Conclusion}

In summary, the study was a comprehensive study' to investigate the burden of fistula in the country's only fistula center, although it was an institutionalized based study. The findings suggest that the incidence of fistula in Eritrea is relatively low as compared to other sub-Saharan countries. Among women in this study, majority of them develop fistula above the age of 18 and their delivery outcome end up with stillbirth delivery, which may indicate that poor access to EmOC has a greater contribution to the problem of obstetric fistula and stillborn baby within Eritrea than teenage delivery. Therefore, given the preventability of the condition, and the devastating consequences of fistula, it is recommended that a strategy be implemented, with the aim of reducing prolonged labor and improving access to a comprehensive emergency obstetric and new born care (CEmONC) at all levels of health system.

\section{Declaration}

\section{Ethics Approval and Consent to Participate}

The study obtained permission from Ministry of Health ethical and research committee, and Mendefera Zonal Referral and National Fistula Hospitals. Each participant's record was checked. The procedure of the study was very 
confidential. The cards of the participants were reviewed and recorded by a medical doctor who works as an Obstetric and gynecologist in the hospital, in order to maintain confidentiality of the information.

\section{Consent for Publication}

Not applicable

\section{Availability of Data and Materials}

The datasets used and/or analysed during the current study are available from the corresponding author on reasonable request.

\section{Abbreviations}

\begin{tabular}{|c|c|}
\hline CEmOC & $\begin{array}{l}\text { Comprehensive emergency obstetric and new } \\
\text { born care }\end{array}$ \\
\hline EHMIS & $\begin{array}{l}\text { Eritrean Health Management Information } \\
\text { System }\end{array}$ \\
\hline EmOC & Emergency obstetric care \\
\hline PHS & Eritrean Population and Health Survey \\
\hline LMIC & Low and middle income countries \\
\hline MZRNFH & $\begin{array}{l}\text { Mendefera Zonal Referral and National Fistula } \\
\text { Hospital }\end{array}$ \\
\hline OF & Obstetrics fistula \\
\hline RVF & Recto-vaginal fistula \\
\hline UGF & Urogenital fistula \\
\hline VVF & Vesico-vaginal fistula \\
\hline WHO & World Health Organization \\
\hline
\end{tabular}

\section{Funding}

This study was funded by the researchers.

\section{Authors Contributions}

DS was involved in the designing and proposal writing of the study, clinical record reviewing for data collection, data analysis, and interpretation of the study findings, report writing, report reviewing and final paper preparation.

$\mathrm{HH}$ was involved in clinical record reviewing for data collection, data analysis, and interpretation of the study findings, report reviewing and final paper preparation.

YI was involved clinical record reviewing for data collection, data analysis and report reviewing

DE was involved in data analysis, and interpretation of the study findings, report reviewing and final paper preparation.

\section{Conflict of Interests}

The authors declare that they have no competing interests.

\section{Acknowledgements}

All authors are thankful to the Ministry of Health, Health facility service division and Mendefera Zonal Referral and
National Fistula Hospital, Eritrea, for giving permission for the study to be conducted.

\section{References}

[1] Ahmed. S, Tunçalp Ö. Burden of obstetric fistula: From measurement to action. The Lancet Global Health- May 2015. DOI: 10.1016/S2214-109X(15)70105-1.

[2] Integrated Management of Pregnancy and Childbirth: Obstetric Fistula: Guiding principles for clinical management and programme development. World Health Organization 2006.

[3] Hilton P, Vesico-vaginal fistulas in developing countries. International Journal of Gynecology and Obstetrics 82 (2003) 285-295. Doi: 10.1016/s0020-7292(03)0022-4.

[4] Bimbola et al. Obstructed Labour: The Main Cause of Vesico-Vaginal Fistula - Review of Literature. European Journal of Research in Medical Sciences Vol. 1 No. 1 September 2013.

[5] Tebeu PM et al. Risk factors for obstetric fistula: a clinical review. Int Urogynecol J. 2012; 23 (4): 387-94. DOI 10.1007/s00192-011-1622-x.

[6] Maheu-Giroux et al. Risk factors for vaginal fistula symptoms in Sub-Saharan Africa: a pooled analysis of national household survey data. BMC Pregnancy and Childbirth BMC series - open, inclusive and trusted 2016, 16: 82. DOI: 10.1186/s12884-016-0871-6.

[7] Adler AJ et al. Estimating the prevalence of obstetric fistula: a systematic review and meta-analysis. BMC Pregnancy Childbirth. 2013; 13: 246.

[8] Tunçalp Ö, Tripathi V, Landry E, Stanton K, Ahmed S. Measuring the incidence and prevalence of obstetric fistula: approaches, needs and recommendations. Bull World Health Organ. 2015; 93: 60-2. doi: http://dx.doi.org/10.2471/BLT.14.141473.

[9] Danso K, Martey J, Wall L, Elkins T. The epidemiology of genitourinary fistulae in Kumasi, Ghana, 1977-1992. Int Urogynecol J Pelvic Floor Dysfunct 1996; 7: 117-120. doi: 10.1007/BF01894198.

[10] Muleta M, Rasmussen S, Kiserud T. Obstetric fistula in 14,928 Ethiopian women. Acta Obstet Gynecol Scand. 2010; 89 (7): $945-51$.

[11] Stanton C, Holtz SA, Ahmed S. Challenges in measuring obstetric fistula. Int J Gynaecol Obstet. 2007; 99 Suppl 1:S4-9. http://dx.doi.org/10.1016/j.ijgo.2007.06.010 pmid: 17765240\}.

[12] Muleta M. Obstetric Fistula in Developing Countries: A Review Article. J Obstet Gynaecol Can 2006; 28 (11): 962 966.

[13] Umeora OUJ, Emma-Echiegu NB (2015) Vesico-Vaginal Fistula in Developing Countries - Time to Turn off The Tap. J Preg Child Health 2:e120. doi: 10.4172.

[14] Hinrichsen, D. Obstetric Fistula: Ending the Silence, Easing the Suffering. INFO Reports, No. 2. Baltimore, Johns Hopkins Bloomberg School of Public Health, The INFO Project, Sept. 2004). 
[15] Karen D. Cowgill, Jennifer Bishop, Amanda K. Norgaard, Craig E. Rubens and Michael G. Gravett. Obstetric fistula in low-resource countries: an under-valued and under-studied problem - systematic review of its incidence, prevalence, and association with stillbirth. BMC Pregnancy and Childbirth 201515: 193. DOI: 10.1186/s12884-015-0592-2.

[16] Maheu-Giroux M et al. Prevalence of symptoms of vaginal fistula in 19 sub-Saharan Africa countries: a meta-analysis of national household survey data. Lancet Glob Health. 2015; 3 (5): e271-8.

[17] M. Stamatakos, C. Sargedi, T. Stasinou \& K. Kontzoglou. Vesicovaginal Fistula: Diagnosis and Management, Indian J $\begin{array}{lllll}\text { Surg } & \text { (March-April 2014) } 76 & \text { (2): } & 131-136 & \text { DOI }\end{array}$ 10.1007/s12262-012-0787-y.

[18] Holme A, Breen M, MacArthur C (2007). Obstetric fistulae: a study of women managed at the Monze Mission Hospital, Zambia. BJOG2007; 114: 1010-1017. DOI: 10.1111/j.14710528.2007.01353.x.

[19] National Statistics Office (NSO) [Eritrea] and Fafo AIS. 2013. Eritrea Population and Health Survey 2010.
[20] HMIS Eritrean Ministry of Health 2018 Annual Report.

[21] Wall, LL. Obstetric vesicovaginal fistula as an international public-health problem. Lancet 2006; 368: 1201.

[22] Raassen, T. J., E. G. Verdaasdonk, and M. E. Vierhout. 2008. "Prospective Results after First-Time Surgery for Obstetric Fistulas in East African Women." International Urogynecology Journal 19 (1): 73-79.

[23] Mary Lake Polan, Ambereen Sleemi, Mulu Muleta Bedane, Svjetlana Lozo, and Mark A Morgan, Obstetric Fistula. Essential Surgery: Disease Control Priorities, Third Edition (Volume 1): 95-108.

[24] Demisew Anemu Sori, Ahadu Workineh Azale, and Desta Hiko Gemeda, Characteristics and repair outcome of patients with Vesicovaginal fistula managed in Jimma University teaching Hospital, Ethiopia. BMC Urol. 2016; 16: 41. Published online 2016 Jul 12. doi: 10.1186/s12894-016-01528. 